\title{
ANÁLISE DA PRODUÇÃO CIENTÍFICA REFERENTE À TEMÁTICA DE SUSTENTABILIDADE EM \\ PESQUISAS DA ADMINISTRAÇÃO
}

\author{
ANALYSIS OF THE SCIENTIFIC LITERATURE ON \\ SUSTAINABILITY IN ADMINISTRATION RESEARCH
}

Recebido em: 16/12/2013 - Aprovado em: 12/03/2014 Avaliado pelo sistema double blind review Editora Científica: Manolita Correia Lima

\author{
MÁRCIA MARTINS MENDES DE LUCA marciadeluca@ufc.br \\ VANESSA INGRID DA COSTA CARDOSO \\ ALESSANDRA CARVALHO DE VASCONCELOS \\ AYRTON BEZERRA PONTES \\ UNIVERSIDADE FEDERAL DO CEARÁ
}

\begin{abstract}
RESUMO
A cada dia o tema sustentabilidade se mostra mais recorrente nas pesquisas na área de Administração, sendo inúmeros os pesquisadores que procuram compreender a sustentabilidade e associá-la ao mundo corporativo. O objetivo geral do presente estudo consiste em investigar as perspectivas teóricas da produção científica em Administração direcionada para o tema nos anais do Encontro da Anpad e na Revista de Gestão Social e Ambiental, em um período de oito anos. A pesquisa abrange a análise das características de autoria, dos procedimentos metodológicos e das bases teóricas, além de características qualitativas dos artigos selecionados. Trata-se de estudo qualiquantitativo, caracterizado como pesquisa descritiva, com aplicação da bibliometria e da Análise de Conteúdo. Foram analisados Io3 artigos publicados no Encontro da Anpad (edições anuais de 2003 a 20Io) e na Revista de Gestão Social e Ambiental (edições quadrimestrais de 2007 a 20I0). Os resultados mostraram um aumento da produção científica sobre sustentabilidade, o que evidencia o amadurecimento da área nessa temática. De forma mais pontual, verificou-se uma tendência para as coautorias; uma diversidade metodológica, não se limitando a teorias ou modelos predefinidos; e uma elevada incidência de propostas de modelos relacionados à sustentabilidade.

Palavras-chave: bibliometria; sustentabilidade; produção científica.
\end{abstract}

\section{ABSTRACT}

Sustainability has become an increasingly popular topic in administration research projects, with a great number of researchers trying to understand and apply it to the corporate world. The general objective of the present study consists of investigating the theoretical perspectives of scientific production on sustainability in administration present in the annals of the Anpad Meeting and in the "Revista de Gestão Social e Ambiental", over an eight-year period. The research encompasses the characteristics of authorship, methodological procedures and theoretical groundwork, as well as the qualitative characteristics of the selected articles. It is a qualitative study, characterized as descriptive research, with the application of bibliometrics and content analysis. 103 articles, published in the Anpad Meeting (annual editions, from 2003 to 2010) and in the "Revista de Gestão Social e Ambiental" (published three times a year, from 2007 to 2010), were analyzed. The results revealed an increase in scientific production on sustainability, demonstrating this topic's growing maturity. In a more punctual way, researchers identified a tendency towards co-authorship; methodological diversity, not limited to theories or pre-defined models; and a high incidence of proposals of models related to sustainability.

Keywords: bibliometrics; sustainability; scientific production. 


\section{INTRODUÇÃO}

São cada dia mais frequentes as pesquisas científicas com abordagem do tema sustentabilidade no contexto da gestão empresarial, tanto no âmbito nacional quanto no contexto internacional (SANTOS; SOUZA; FALKEMBACH, 2008). Nesse sentido, diversos pesquisadores procuram compreender a sustentabilidade, bem como associá-la ao mundo corporativo, sob várias perspectivas. Isso advém da crescente cobrança da sociedade quanto à postura das empresas em relação à comunidade e ao ambiente em que atuam. Tal expectativa contempla um elenco de providências, compreendendo ações socialmente responsáveis, emprego de processos produtivos com tecnologia limpa, ações que visem mitigar os impactos ambientais causados pela atividade empresarial, transparência e ética na continuidade das operações, assim como atendimento aos interesses dos diferentes stakeholders.

Esse cenário dinâmico, no qual as estratégias de negócios relacionamse a outros aspectos que vão além da busca pela lucratividade, caracteriza um mercado cada dia mais complexo, pois demanda das empresas a capacidade de se adaptar às necessidades dos diversos agentes do mercado. Souza, Murcia e Marcon (20II) ressaltam que esse cenário mercadológico é extremamente competitivo, e que, além das demandas do mercado, as empresas procuram atender à legislação vigente e aos quesitos ambientais e sociais. Complementarmente, salientam os autores que as empresas podem conseguir novas oportunidades de negócios e até redução de custos por meio da melhoria do desempenho ambiental, criando vantagem competitiva. Segundo Barbieri (2007), a adaptação da gestão às demandas do meio ambiente representa um grande desafio para as empresas.

Esse contexto desperta a atenção e a curiosidade no âmbito acadêmico, em que estudiosos procuram entender a temática sustentabilidade empresarial, considerando sua relevância na permanente busca pelo melhor ambiente empresarial, no qual a continuidade das organizações fundamenta-se nos pilares econômico, social e ambiental (SOUZA; MURCIA; MARCON, 2OII). A congruência desses três pilares frente à mudança do paradigma das organizações, antes voltadas exclusivamente para a obtenção do lucro, 
deu origem ao Triple Bottom Line (TBL), também conhecido como tripé da sustentabilidade (BARBOSA, 2007). No contexto corporativo, о TBL, segundo Lages, Lages e França (2010, p. I8), "reflete um conjunto de valores, objetivos e processos que uma organização deve focar para criar valor em três dimensões: econômica, social e ambiental”. Logo, o referido conceito permite que a análise da sustentabilidade empresarial se faça com base em fatores inerentes a cada uma das três dimensões propostas.

Levando-se em conta esses três pilares, pode-se afirmar que o debate acerca dos temas relacionados à sustentabilidade e o interesse por parte das empresas, governos e consumidores encontram-se em franco desenvolvimento, tanto no meio acadêmico quanto no contexto empresarial. Dessa forma, o tema sustentabilidade vem adquirindo especial importância, à medida que é empreendida relevância também à preservação do meio ambiente, com a consequente disposição para discussões e polêmicas envolvendo empresários, formuladores de políticas e comunidade acadêmica (OLIVeIra; BORGes; JABbOUR, 2005; PEReira et al., 20II). É sob essa motivação que o presente estudo propõe empreender uma análise bibliométrica, método que permite analisar a evolução da produção científica sobre um tema - sustentabilidade, no caso em foco.

Nesse contexto, o estudo se norteia pela seguinte questão de pesquisa: Que tratamentos metodológicos e perspectivas teóricas são aplicados aos estudos sobre sustentabilidade publicados em periódicos e em anais de eventos nacionais de Administração nos últimos oito anos?

O objetivo da pesquisa consiste em investigar as perspectivas teóricas da produção científica em Administração direcionada para o tema nos anais do Encontro da Associação Nacional de Pós-Graduação e Pesquisa em Administração (EnAnpad) e na Revista de Gestão Social e Ambiental, em um período de oito anos.

O presente estudo se justifica pelo crescimento da preocupação com o meio ambiente e a preservação de recursos naturais essenciais para a perpetuação da vida em sociedade, concomitantemente ao desenvolvimento empresarial. Dessa forma, torna-se relevante investigar as principais características das pesquisas que abordam a sustentabilidade no âmbito dos pesquisadores da 
gestão empresarial, para subsidiar pesquisas futuras. Ressalte-se ainda que, baseado em levantamento prévio, foram identificadas poucas pesquisas acerca da produção científica sob o enfoque da sustentabilidade.

Segundo Oliveira (2002), a análise da produção científica é essencial para subsidiar o estabelecimento e o acompanhamento de uma política nacional de ensino e pesquisa, pois propicia um diagnóstico das reais potencialidades de determinados grupos e/ou instituições. Logo, é relevante, na área administrativa, realizar pesquisas que explorem o tema sustentabilidade por meio da análise da produção científica.

Para alcançar os objetivos propostos, realizou-se uma pesquisa descritiva, de natureza qualiquantitativa, por meio da aplicação da bibliometria e da Análise de Conteúdo nos artigos componentes da amostra. O estudo abrangeu as oito edições anuais do Encontro da Associação Nacional de Pós-Graduação e Pesquisa em Administração (EnAnpad), no período 2003-20I0, e as doze edições quadrimestrais da Revista de Gestão Social e Ambiental, referentes ao período 2007-2010, ambos conceituados nas áreas de Administração, Contabilidade e Turismo, por contemplarem a temática em estudo. De um total de 23r artigos, após exclusão de 128 por terem aplicado o tema em outras áreas de conhecimento, sem abordagem de gestão, a amostra resultou na reunião de I03 artigos selecionados com base na citação de palavras-chave previamente definidas, relacionadas com a temática. 


\section{REFERENCIAL TEÓRICO}

\section{SUSTENTABILIDADE EMPRESARIAL}

Nas últimas décadas, o meio empresarial vem sofrendo mudanças decorrentes de uma demanda mais social, a qual exige das empresas uma adaptação a um novo modelo de expansão de capital, adotando uma postura mais responsável perante o meio em que atuam. Tais mudanças são originadas não apenas de novos padrões de consumo, mas também da conjugação de elementos que sugerem a substituição de alguns paradigmas de gestão, de maneira que as empresas não mais se limitem às dimensões de lucratividade. Dessa forma, observa-se a necessidade de que as empresas passem a conciliar as abordagens econômica, social e ambiental.

Nesse contexto, emerge o conceito de sustentabilidade empresarial, o qual pressupõe a adoção de práticas por meio das quais as empresas possam suprir as necessidades atuais sem comprometer a capacidade das gerações futuras no que tange ao atendimento de suas demandas, e que, além disso, garantam uma boa imagem mercadológica para seus produtos e serviços, ao demonstrar respeito e preocupação com as condições ambientais e da sociedade.

A sustentabilidade é um tema em permanente discussão no meio acadêmico e em transição contínua no meio empresarial, haja vista que a cada dia mais as empresas vêm se adaptando às práticas sustentáveis. De acordo com Machado, Nascimento e Murcia (2009, p. 26), a sustentabilidade se caracteriza como um conceito "interdisciplinar, uma vez que é usado em várias áreas do conhecimento. A sustentabilidade pode ser entendida como uma questão de se estabelecer distribuição igualitária de bem-estar associado aos recursos naturais nas dimensões inter e intratemporal”.

O conceito de sustentabilidade empresarial perpassa a gestão, com o objetivo de assegurar o sucesso empresarial em longo prazo e, concomitantemente, auxiliar o desenvolvimento socioeconômico da comunidade, visando à preservação do meio ambiente e a uma sociedade mais equilibrada (CORREA et al., 20Io). Nesse sentido, tal conceito contempla 
uma gestão empresarial integrada, cuja capacidade está voltada para o equilíbrio das relações entre as necessidades econômicas, ambientais e sociais, no longo prazo (RODRIGUes, 2005; DELAI; TAKAJASHI, 2008; FARIAS; FARIAS, 2009). Conforme Ladeira, Santini e Araujo (2012, p. 736), a sustentabilidade representa um conhecimento que considera e "reconhece a complexidade do sistema dinâmico, a robustez social, as mais diversas culturas e a incorporação de critérios normativos, que podem ser adaptados e alterados em diferentes contextos".

Assim, além de conciliar a operacionalização de práticas socialmente responsáveis com a preservação do meio ambiente, a sustentabilidade empresarial se caracteriza pela gestão eficiente, responsável e sustentável, gerando benefícios para todas as partes interessadas, que investem recursos financeiros, produzem ou utilizam serviços, ao mesmo tempo em que resguardam o ambiente onde atua a empresa.

O desenvolvimento do conceito de sustentabilidade levou as principais bolsas de valores do mundo a criar carteiras de índices de sustentabilidade empresarial, cuja composição se dá com ações de empresas que realizam práticas socialmente responsáveis e de sustentabilidade. Nesse contexto, foram então criados os primeiros índices: Dow Jones Sustainability Index (Nova Iorque, 1999), FTSE4Good (Londres, 200I), Socially Responsible Investment Index (SRI Index) ou Índice de Investimento Socialmente Responsável (Joanesburgo, 2004) e Índice de Sustentabilidade Empresarial (ISE) (Brasil, 2005).

No âmbito acadêmico, também houve uma mobilização quanto à emergência do conceito de sustentabilidade. No contexto nacional, as pesquisas sobre o tema foram impulsionadas na década de 1990 (PARENTE; FERREIRA, 2007; SOUZA et al., 20II).

\section{BIBLIOMETRIA E SUSTENTABILIDADE}

O presente tópico aborda alguns dos estudos bibliométricos que revelam aspectos da investigação da produção científica sobre sustentabilidade.

Atualmente, a produção científica se encontra em estágio avançado, no qual a comunicação é facilitadora e as diversas possibilidades tecnológicas 
são agregadoras do desenvolvimento do conhecimento científico. Segundo Oliveira (2002, p. 69), a comunicação científica "é importante para a aceitação do que é produzido cientificamente como constituinte do conhecimento científico”. Conforme Correa et al. (2010), os pesquisadores têm interesse permanente em publicar os resultados de seus estudos científicos, visando contribuir para o desenvolvimento do conhecimento. Dentre os meios de comunicação mais utilizados, para a publicação de trabalhos científicos, tanto no contexto nacional quanto no âmbito internacional, destacam-se os congressos acadêmicos e as publicações periódicas especializadas (BEUREN; SOUZA, 2008; ARAÚJO; OLIVEIRA; SILVA, 2009).

De acordo com De Luca et al. (20II), o incremento da produção científica fez surgir novos desafios e a necessidade de estudos que possam compreender tal fenômeno, ou seja, com enfoque bibliométrico. Emergem, portanto, os trabalhos realizados com característica de bibliometria. Esta, segundo Silva, Toledo Filho e Pinto (2009) vem sendo aplicada como ferramenta para avaliar a produção científica. Segundo os referidos autores, o levantamento dos trabalhos científicos, nas mais variadas áreas do conhecimento, requer uma busca criteriosa, devido à frequente emergência de novos conhecimentos. Além disso, ressalta-se a necessidade de que a bibliometria seja conduzida com elevado rigor metodológico, para cumprir a sua finalidade.

No sentido de disseminar o conhecimento científico, tem sido frequente a publicação de estudos bibliométricos em periódicos especializados das diversas áreas do conhecimento, seja no âmbito nacional (OLIVEIRA, 2002; THEÓPHILO, 2004; CARDOSO ET AL., 2005; BEUREN; SOUZA, 2008; ROSA; ENSSLIN, 2007; SGARBI et al., 2008; SANTOS; SOUZA; FALKEMBACH, 2008; GALLON et al., 2008; JABBOUR; SANTOS; BARBIERI, 2008; LEITE FILHO, 2008; MORETTI; CAMPANÁRIO, 2009; NASCIMENTO et al., 2009; MACHADO; NASCIMENTO; MURCIA, 2009; VELTER et al., 20Io; SOUZA et al., 20II; PEREIRA et al., 20II; AFONSO et al., 20II) seja no contexto internacional (SUBRAMANYAM, I983; CHUNG; PAK; COX, I992; RODGERS; WILLIAMS, I996; ZEFF, I996; FOGARTY, 2004; SIN, 20II). Devido à intensificação de abordagens acerca da sustentabilidade, faz-se necessário verificar de que forma a temática é tratada pelos pesquisadores e o que é publicado em congressos e periódicos. 


\section{\& OUTROS}

Afirmam Souza et al. (20II) que o tema se consolidou a partir do início do século atual, nos principais congressos e periódicos do país, culminando na maior realização de estudos sobre a produção científica em sustentabilidade. Foram identificadas diversas matérias voltadas para a investigação do tratamento acadêmico do tema nos últimos anos (ROSA; ENSSLIN, 2007; SGARBI et al., 2008; SANTOS; SOUZA; FALKEMBACH, 2008; GALLON et al., 2008; JABBOUR; SANTOS; BARBIERI, 2008; MORETTI; CAMPANÁRIO, 2009; NASCIMENTO et al., 2009; MACHADO; NASCIMENTO; MURCIA, 2009; VELTER et al., 20IO; SOUZA et al., 20II; PEREIRA et al., 20II; A FONSO et al., 20II; SOUZA et al., 20I3).

O Quadro I apresenta sinteticamente o foco do estudo e as principais conclusões de algumas pesquisas bibliométricas que destacaram o tema sustentabilidade.

Quadro I Pesquisas bibliométricas sobre sustentabilidade

\begin{tabular}{|c|c|c|c|c|}
\hline Autoria (ano) & Foco de estudo & Unidade de análise & $\begin{array}{l}\text { Período } \\
\text { de análise }\end{array}$ & Principais conclusões \\
\hline $\begin{array}{l}\text { Rosa e Ensslin } \\
\text { (2007) }\end{array}$ & $\begin{array}{l}\text { Gestão ambien- } \\
\text { tal }\end{array}$ & $\begin{array}{l}\text { Engema, EnAnpad, } \\
\text { SBPO e Congresso } \\
\text { USP de Controlado- } \\
\text { ria e Contabilidade }\end{array}$ & $2005-$ & $\begin{array}{l}\text { Inserção da gestão ambien- } \\
\text { tal no âmbito estratégico } \\
\text { das empresas e das políticas } \\
\text { públicas. Vasta concentração } \\
\text { dos trabalhos quanto à abor- } \\
\text { dagem em gestão da susten- } \\
\text { tabilidade ambiental. }\end{array}$ \\
\hline $\begin{array}{l}\text { Sgarbi et al. } \\
\text { (2008) }\end{array}$ & $\begin{array}{l}\text { Sustentabili- } \\
\text { dade }\end{array}$ & $\begin{array}{l}\text { EnAnpad, Simpep } \\
\text { e revistas RAC-e, } \\
\text { READ-e, RAE-e e } \\
\text { Gestão.Org }\end{array}$ & $\begin{array}{l}2003- \\
2007\end{array}$ & $\begin{array}{l}\text { Enquanto o número de publi- } \\
\text { cações acerca da sustenta- } \\
\text { bilidade aumenta nos anais } \\
\text { de congressos, diminui nos } \\
\text { periódicos. }\end{array}$ \\
\hline $\begin{array}{l}\text { Santos, Souza } \\
\text { e Falkembach } \\
\text { (2008) }\end{array}$ & $\begin{array}{l}\text { Responsabili- } \\
\text { dade social cor- } \\
\text { porativa }\end{array}$ & EnAnpad & $\begin{array}{l}1998- \\
2007\end{array}$ & $\begin{array}{l}\text { É crescente o interesse pelo } \\
\text { tema. A maioria dos traba- } \\
\text { lhos são pesquisas empíricas. } \\
\text { Ações de RSC são utilizadas } \\
\text { para obtenção de legitimi- } \\
\text { dade social. A maioria dos } \\
\text { estudos se fundamenta na } \\
\text { percepção de apenas alguns } \\
\text { stakeholders das empresas. }\end{array}$ \\
\hline
\end{tabular}




\begin{tabular}{|c|c|c|c|c|}
\hline Autoria (ano) & Foco de estudo & Unidade de análise & $\begin{array}{l}\text { Período } \\
\text { de análise }\end{array}$ & Principais conclusões \\
\hline $\begin{array}{l}\text { Gallon et al. } \\
\text { (2008) }\end{array}$ & $\begin{array}{l}\text { Temática } \\
\text { ambiental }\end{array}$ & $\begin{array}{l}\text { EnAnpad e diversos } \\
\text { periódicos Qualis, } \\
\text { daCapes }\end{array}$ & $\begin{array}{l}2000- \\
2006\end{array}$ & $\begin{array}{l}\text { Identificou-se a perspectiva } \\
\text { de inserção internacional, } \\
\text { uso significativo de livros nas } \\
\text { referências, eventos que são } \\
\text { referenciados como não clas- } \\
\text { sificados no Qualis da Capes. }\end{array}$ \\
\hline $\begin{array}{l}\text { Jabbour, Santose } \\
\text { Barbieri (2008) }\end{array}$ & $\begin{array}{l}\text { Gestão ambien- } \\
\text { tal empresarial }\end{array}$ & $\begin{array}{l}\text { RAE, RAE-e, RAUSP, } \\
\text { RAP, REAd e RAC }\end{array}$ & $\begin{array}{l}1996- \\
2005\end{array}$ & $\begin{array}{l}\text { A produção em gestão } \\
\text { ambiental corresponde a } \\
\text { 2,3\% da produção em Admi- } \\
\text { nistração, com concentração } \\
\text { em alguns pesquisadores e } \\
\text { significativa fundamentação } \\
\text { em estudos internacionais. }\end{array}$ \\
\hline $\begin{array}{l}\text { Moretti e Campa- } \\
\text { nário (2009) }\end{array}$ & $\begin{array}{l}\text { Responsabi- } \\
\text { lidade social } \\
\text { empresarial }\end{array}$ & EnAnpad & $\begin{array}{l}1997- \\
2007\end{array}$ & $\begin{array}{l}\text { Identificou-se maturidade } \\
\text { científica dos autores e con- } \\
\text { senso quanto aos conceitos } \\
\text { relacionados ao tema. }\end{array}$ \\
\hline $\begin{array}{l}\text { Nascimento et al. } \\
\text { (2009) }\end{array}$ & $\begin{array}{l}\text { Disclosure } \\
\text { social e ambien- } \\
\text { tal }\end{array}$ & $\begin{array}{l}\text { Periódicos no portal } \\
\text { da Capes que apre- } \\
\text { sentaram a palavra } \\
\text { "accounting" no } \\
\text { título }\end{array}$ & $\begin{array}{l}1997- \\
2007\end{array}$ & $\begin{array}{l}\text { Odisclosure ambiental é mais } \\
\text { explorado, e os principais } \\
\text { centros de pesquisa são loca- } \\
\text { lizados no Reino Unido, Esta- } \\
\text { dos Unidos, Canadá e Nova } \\
\text { Zelândia. }\end{array}$ \\
\hline $\begin{array}{l}\text { Machado, Nasci- } \\
\text { mento e Murcia } \\
\text { (2009) }\end{array}$ & $\begin{array}{l}\text { Contabilidade } \\
\text { social e ambien- } \\
\text { tal }\end{array}$ & $\begin{array}{l}\text { EnAnpad, Con- } \\
\text { gresso USPe } \\
\text { Anpcont }\end{array}$ & $2004-$ & $\begin{array}{l}\text { Concentração de pesquisas } \\
\text { sobre disclosure social elou } \\
\text { ambiental. Pesquisa docu- } \\
\text { mental foi mais frequente e a } \\
\text { maioria dos autores publicou } \\
\text { apenas uma vez sobre o tema. }\end{array}$ \\
\hline Velter et al. (2010) & $\begin{array}{l}\text { Sustentabili- } \\
\text { dade }\end{array}$ & $\begin{array}{l}\text { Banco de dados } \\
\text { do sistema Web of } \\
\text { Science }\end{array}$ & $\begin{array}{l}2000- \\
2010\end{array}$ & $\begin{array}{l}\text { Os Estados Unidos detêm a } \\
\text { maior parte das publicações. } \\
\text { O inglês é o idioma predomi- } \\
\text { nante. }\end{array}$ \\
\hline Souza et al. (2011) & $\begin{array}{l}\text { Sustentabili- } \\
\text { dade ambiental }\end{array}$ & $\begin{array}{l}\text { Periódicos (nacio- } \\
\text { nais) classificados } \\
\text { como } A 1, A 2, B 1 \text { e } B 2\end{array}$ & $\begin{array}{l}2007- \\
2009\end{array}$ & $\begin{array}{l}\text { Concentração de abordagem } \\
\text { em alguns periódicos, com } \\
\text { destaque para a temática } \\
\text { gestão ambiental e realização } \\
\text { de mais pesquisas qualitativas } \\
\text { com tendência para a emer- } \\
\text { gência da quantitativa. }\end{array}$ \\
\hline $\begin{array}{l}\text { Pereira et al. } \\
\text { (2011) }\end{array}$ & $\begin{array}{l}\text { Sustentabili- } \\
\text { dade socioam- } \\
\text { biental }\end{array}$ & $\begin{array}{l}\text { International Jour- } \\
\text { nal of Operations } \\
\text { \& Production Man- } \\
\text { agement }\end{array}$ & 2003 & $\begin{array}{l}\text { Crescente abordagem do } \\
\text { tema com discussão princi- } \\
\text { palmente quanto à estratégia } \\
\text { de manufatura. }\end{array}$ \\
\hline
\end{tabular}




\begin{tabular}{|c|c|c|c|c|}
\hline Autoria (ano) & Foco de estudo & Unidade de análise & $\begin{array}{l}\text { Período } \\
\text { de análise }\end{array}$ & Principais conclusões \\
\hline $\begin{array}{l}\text { Afonso et al. } \\
\text { (2011) }\end{array}$ & $\begin{array}{l}\text { Sustentabili- } \\
\text { dade }\end{array}$ & $\begin{array}{l}\text { Base de dados Por- } \\
\text { tal da Capes: Scopus, } \\
\text { ISI Web of Knowl- } \\
\text { edge, Science Direct } \\
\text { eEBSCO }\end{array}$ & $\begin{array}{l}2001- \\
2011\end{array}$ & $\begin{array}{l}\text { A publicação de artigos } \\
\text { científicos na área é ainda } \\
\text { incipiente, mas tem apresen- } \\
\text { tado grande crescimento na } \\
\text { última década, e levanta as } \\
\text { principais características com } \\
\text { relação a autores, periódicose } \\
\text { relevância científica das publi- } \\
\text { cações. }\end{array}$ \\
\hline Souza et al. (2013) & $\begin{array}{l}\text { Responsabi- } \\
\text { lidade social } \\
\text { empresarial }\end{array}$ & $\begin{array}{l}\text { Teses e disserta- } \\
\text { ções de programas } \\
\text { stricto sensu em } \\
\text { Administração }\end{array}$ & 2009 & $\begin{array}{l}\text { Verificou-se evolução quanti- } \\
\text { tativa em relação ao total de } \\
\text { trabalhos defendidos na área, } \\
\text { principalmente nos últimos } \\
\text { cinco anos da análise. Pre- } \\
\text { dominância de estudos nos } \\
\text { temas responsabilidade social, } \\
\text { governança corporativa, ética, } \\
\text { sustentabilidade empresarial } \\
\text { e mercado de baixa renda. }\end{array}$ \\
\hline
\end{tabular}

De acordo como Quadro I, há diversas abordagens dos estudos bibliométricos em sustentabilidade. Observa-se ainda que as pesquisas abrangem um longo período, revelando a evolução da produção científica sobre o tema. 


\section{METODOLOGIA}

Este estudo se caracteriza como pesquisa descritiva, levando-se em conta a descrição dos principais indicadores da produção científica acerca da sustentabilidade. Para o alcance dos objetivos delineados, foram aplicadas técnicas de pesquisa bibliométrica e a Análise de Conteúdo. A bibliometria consiste em uma técnica quantitativa e estatística para a medição da produção e disseminação do conhecimento científico (FONSECA I986; MACIASCHAPUlA, 1998). A análise bibliométrica se desenvolve em quatro etapas básicas, a saber: a escolha da literatura a ser analisada, a avaliação dos dados coletados, a análise e interpretação das informações e a apresentação dos resultados (COOPER; LINDSAY, I998).

Além da bibliometria, realizou-se a Análise de Conteúdo, que, segundo Bardin (2004), representa um conjunto de técnicas de análise das comunicações, que procura obter informações relativas às características das mensagens disponibilizadas e possibilitar a inferência acerca de conhecimentos relativos à percepção dessas mensagens. Nesse sentido, o presente estudo foi desenvolvido na perspectiva de investigar as principais mensagens relacionadas à sustentabilidade da produção científica na área de Administração.

No que concerne à abordagem, a pesquisa é classificada como qualiquantitativa, já que, além de se efetuar a Análise de Conteúdo para verificar as características do estudo, efetua-se também o emprego de quantificação tanto nas modalidades de coleta de informações, quanto no seu tratamento por meio de técnicas estatísticas (RICHARDSON, 2009).

Para viabilização deste estudo, foram consideradas as publicações do período de 2003 a 20Io, contemplando artigos publicados nos anais do EnAnpad (2003 a 20I0) e nas edições quadrimestrais da Revista de Gestão Social e Ambiental - RGSA (2007 a 20I0). Vale ressaltar que o período foi definido levando-se em conta a emergência da relevância do tema e, consequentemente, da sua aplicabilidade em pesquisas científicas, nos últimos anos. Pode-se perceber tal relevância após o surgimento da área temática específica de Gestão Social e Ambiental, no EnAnpad, em 2003, e 
da inserção do tema estratégia e sustentabilidade socioambiental, na área temática Estratégia em Organizações, no referido evento, em 2009.

A escolha do Encontro da Anpad se deu por sua relevância na área administrativa, sendo um evento de grande reconhecimento (SANTOS; SOUZA; FALKEMBACH, 2008; MORETTI; CAMPANÁRIO, 2009). Quanto aO periódico, procurou-se selecionar um com linha editorial específica para os temas gestão socioambiental e sustentabilidade, e que obteve, na classificação do sistema Qualis/CAPES do triênio 20I0-20I2 um conceito B2, evidenciando que a busca pela ampliação da discussão e disseminação do tema socioambiental está sendo desempenhada cientificamente a contento. Conforme informações disponíveis no site da RGSA, a revista visa ampliar a discussão e disseminação da temática socioambiental, resultante de pesquisas acadêmicas e possui linha editorial assentada em temas que dizem respeito especificamente às áreas de gestão e de política socioambientais das organizações (RGSA, 2013). A escolha do periódico justifica-se ainda na medida em que, de acordo com o Qualis/CAPES do triênio em questão, com classificação semelhante ou superior à RGSA encontram-se os periódicos Engenharia Sanitária e Ambiental (A2), Revista Ambiente \& Água (BI), Revista em Agronegócios e Meio Ambiente (BI), Engenharia Ambiental (B2) e Revista em Agronegócio e Meio Ambiente (B2) que, em linhas gerais, apresentam focos mais direcionados à engenharia e ao agronegócio.

Para a catalogação das matérias relacionadas às áreas temáticas relativas à sustentabilidade (gestão social e ambiental e estratégia e sustentabilidade socioambiental), foram consultados os anais das oito edições do EnAnpad e as doze edições quadrimestrais da Revista de Gestão Social e Ambiental, nos períodos já mencionados. Os artigos foram obtidos por meio de CD-ROMS dos anais do evento e de acesso ao website da revista.

A seleção dos artigos deu-se por meio da identificação de palavras-chave e respectivas traduções nos títulos e nos resumos dos trabalhos, dentre as seguintes: sustentabilidade, desempenho ambiental, desempenho social, desempenho socioambiental, desenvolvimento sustentável, responsabilidade ambiental, responsabilidade social, responsabilidade socioambiental e Triple Bottom Line. 
Os 23I artigos com as características acima mencionadas foram analisados um a um, para se verificar a aplicabilidade do conceito de sustentabilidade e seus aspectos inerentes à área administrativa, o que resultou em uma amostra de I03 artigos, já que alguns não tratavam do tema sustentabilidade pela ótica da gestão empresarial, mas sim abordando elementos específicos da sustentabilidade inerentes a outras áreas do conhecimento. Vale ressaltar que a seleção de artigos se fez por meio de identificação das palavras no título, resumo e palavras-chave dos 23I artigos. Contudo, percebeu-se que, mesmo com tais palavras presentes, alguns artigos tratavam do tema aplicado em outras áreas de conhecimento, mais específicas, como educação ou práticas de sustentabilidade implantadas no setor agrário, sem abordagem de gestão. Como exemplos, citam-se os artigos intitulados 'O setor de base florestal da serra catarinense e a emergência de um ecossistema industrial', 'Avanços e percalços no cálculo da pegada ecológica municipal: um estudo de caso' e 'Contribuições dos centros familiares de formação por alternância para o desenvolvimento rural sustentável', publicados nas fontes de pesquisa consideradas neste estudo.

A Tabela I apresenta a distribuição da citada amostra, por fonte e ano, no período 2003-20Io.

Tabela I Distribuição anual e total dos artigos coletados e analisados, por fonte (2003 a 2010)

\begin{tabular}{|lllllll|} 
Ano & EnAnpad & \multicolumn{7}{c}{ Revista de Gestão Social e Ambiental } & Geral \\
& Coletados & Analisados & Coletados & Analisados & Coletados & Analisados \\
\hline 2003 & 17 & 3 & - & - & 17 & 3 \\
2004 & 19 & 5 & - & - & 19 & 5 \\
\hline 2005 & 18 & 8 & - & - & 18 & 8 \\
\hline 2006 & 26 & 12 & - & - & 26 & 12 \\
\hline 2007 & 25 & 10 & 14 & 14 & 39 & 24 \\
\hline 2008 & 31 & 10 & 17 & 4 & 48 & 14 \\
\hline 2009 & 22 & 16 & 20 & 12 & 42 & 28 \\
\hline 2010 & 2 & 2 & 20 & 7 & 22 & 9 \\
\hline Total & 160 & 66 & 71 & 37 & 231 & 103 \\
\hline
\end{tabular}




\section{\& OUTROS}

De acordo com a Tabela I, é significativa a representatividade dos artigos publicados nos anais do EnAnpad, correspondendo a 64,I\% da amostra. Observa-se também que no triênio 2007-2009 registrou-se uma concentração dos artigos publicados nas duas modalidades, também na proporção de 64,I\%, sinalizando uma trajetória ascendente no período em análise.

Uma vez definidos os artigos da amostra, a análise levou em conta quatro categorias: (I) autoria, (II) vínculo institucional dos autores, (III) características metodológicas da pesquisa e (IV) base teórica e informações qualitativas da pesquisa. O Quadro 2 apresenta o detalhamento de cada uma das quatro categorias de análise.

Quadro 2 Categorias de análise da pesquisa

\begin{tabular}{|ll}
\hline Categoria & Descrição \\
\hline $\begin{array}{l}\text { Autoria e vínculo institucional do } \\
\text { autor (ou coautores) }\end{array}$ & $\begin{array}{l}\text { Quantidade de autores; Nomes dos autores; Gênero (feminino ou } \\
\text { masculino); Titulação; Área de formação; Cooperação entre IES; } \\
\text { Nome da IES; Estado da IES. }\end{array}$ \\
$\begin{array}{ll}\text { Características metodológicas da } \\
\text { pesquisa }\end{array}$ & $\begin{array}{l}\text { Tipo (teórica, empírica ou teórico/empírica); Natureza (qualitativa, } \\
\text { quantitativa ou qualiquantitativa); Técnicas de análise aplicadas; } \\
\text { Fontes de coleta de dados. }\end{array}$ \\
Buse teórica e informações & $\begin{array}{l}\text { Base teórica utilizada na pesquisa; Abordagem da sustentabilidade } \\
\text { (ambiental, social ou socioambiental); Diretrizes socioambientais } \\
\text { citadas no referencial teórico Dimensões da sustentabilidade (eco- } \\
\text { nômica, social, ambiental); Medidas ou métricas para mensuração } \\
\text { do desempenho ambiental, desempenho social elou desempenho } \\
\text { socioambiental; Definição constitutiva dos termos desenvolvi- } \\
\text { mento sustentável, responsabilidade socioambiental, sustentabi- } \\
\text { lidade e Triple Bottom Line. }\end{array}$ \\
\hline
\end{tabular}

Com base nessas categorias, foi procedida uma análise qualitativa dos artigos, assim como a análise bibliométrica. Os dados coletados foram organizados no instrumento de pesquisa e compilados em ilustrações, com o auxílio do software Microsoft Office Excel. 


\section{APRESENTAÇÃO E ANÁLISE DOS RESULTADOS}

\section{AUTORIA E VÍNCULO INSTITUCIONAL DOS AUTORES}

No que tange à autoria dos artigos, verificou-se que mais de $82 \%$ foram desenvolvidos em coautoria, alguns envolvendo mais de um parceiro. Além disso, verificou-se uma tendência de aumento do número médio de autores por artigo, conforme pode ser observado no Gráfico I.

Gráfico I Média de autores por artigo (2003-2010)

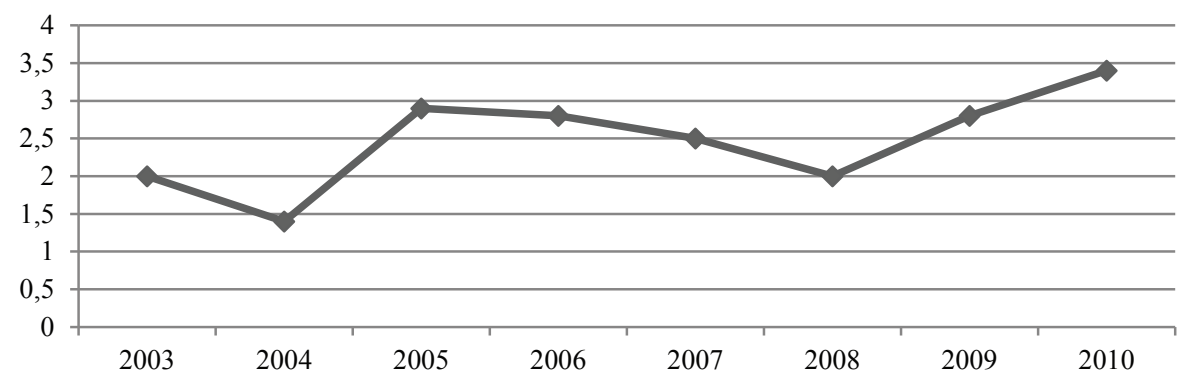

De acordo com o Gráfico I, a média de autores por artigo, que era de dois em 2003, ultrapassa três ou quatro em 20Io, numa demonstração de que nos últimos anos as pesquisas vêm sendo realizadas preferencialmente em parceria.

A quantidade de coautores por artigo varia entre um e cinco, sendo mais comuns estudos com dois e três parceiros. Dentre os raros artigos com cinco coautores, predominam matérias incluídas nos anais do EnAnpad. Segundo Subramanyam (1983), a colaboração entre coautores representa um dos indicadores de qualidade da pesquisa, sobretudo em temas interdisciplinares como a sustentabilidade.

Os dados da pesquisa revelam ainda a predominância do gênero masculino na autoria dos artigos, correspondente a aproximadamente $59 \%$ da amostra. Esse resultado corrobora os dados da pesquisa de De Luca 


\section{\& OUTROS}

et al. (20II), que identificou uma tímida participação feminina na produção científica publicada em eventos nacionais no período de 2004 a 2009. Além disso, os citados autores constataram uma queda da participação feminina na autoria de artigos inseridos nos anais do EnAnpad.

Analisou-se também a titulação dos autores dos artigos da amostra, na busca de se verificar se prevalecem os detentores de títulos de níveis mais elevados. Os autores com titulação mais elevada, ou seja, os doutores representaram parcela mais expressiva de participação (II5), seguida de estudantes de pós-graduação (mestrandos 43 e doutorandos 19), evidenciandose, de certa forma, a vinculação da produção acadêmica aos cursos de pósgraduação stricto sensu (RAVELLI et al., 2009).

A Tabela 2 apresenta os quatro autores que, individualmente ou em coautoria, publicaram as maiores quantidades de artigos nos dois tipos de mídia da amostra, no período analisado.

Tabela 2 Ranking dos quatro autores que mais publicaram artigos da amostra, distribuídos por número de estudos

\begin{tabular}{|lll|}
\hline Ordem & Autor & Quantidade de artigos \\
\hline $1^{\circ}$ & Celso Funcia Lemme & 5 \\
\hline $2^{\circ}$ & Luciano Barin Cruz & 4 \\
\hline $3^{\circ}$ & Elvira Cruvinel Ferreira Ventura & 3 \\
\hline $3^{\circ}$ & Maísa de Souza Ribeiro & 3 \\
\hline
\end{tabular}

De acordo com a Tabela 2, não há concentração de autoria no que concerne aos artigos de sustentabilidade analisados. Segundo Souza et al. (20II), a elevada proporção de coautores por estudo revela a maturidade da área, já que as mais consolidadas possuem pesquisadores com maior concentração de artigos, haja vista que a área é mais explorada. Sob essa perspectiva, o presente estudo verificou que a área temática analisada ainda pode ser classificada como imatura, requerendo, portanto, mais discussão teórica e prática.

mostra-se relevante, ainda, levantar as instituições de ensino superior (IES) de origem dos pesquisadores que publicaram artigos sobre o tema nos dois grupos de veículos analisados (Tabela 3). 
Tabela 3 Ranking das dez IES com as maiores quantidades de autores de artigos participantes da amostra, distribuídas por número de autores Quantidade e Proporção (\%)

\begin{tabular}{|llll|}
\hline Ordem & IES & Quantidade & Proporção (\%) \\
\hline $1^{\circ}$ & Universidade de São Paulo (USP) & 20 & 9,0 \\
\hline $2^{\circ}$ & Universidade Federal do Rio de Janeiro (UFRJ) & 13 & 5,9 \\
\hline $3^{\circ}$ & Universidade Federal do Rio Grande do Sul (UFRGS) & 12 & 5,4 \\
\hline $4^{\circ}$ & Fundação Getúlio Vargas (FGV) & 12 & 5,4 \\
\hline $5^{\circ}$ & Universidade Federal de Santa Catarina (UFSC) & 12 & 5,4 \\
\hline $6^{\circ}$ & Universidade Federal do Ceará (UFC) & 10 & 4,5 \\
\hline $7^{\circ}$ & Universidade Federal do Paraná (UFPR) & 8 & 3,6 \\
\hline $8^{\circ}$ & Universidade Federal da Bahia (UFBA) & 6 & 2,7 \\
\hline $9^{\circ}$ & Universidade de Fortaleza (Unifor) & 6 & 2,7 \\
\hline $10^{\circ}$ & Universidade Nove de Julho (Uninove) & 6 & 2,7 \\
\hline $11^{\circ}$ até o último & Outras & 116 & 52,7 \\
\hline Total & & 221 & 100,0 \\
\hline
\end{tabular}

$\mathrm{Na}$ Tabela 3, verifica-se que as IES ocupantes das cinco primeiras posições do ranking (USP, UFRJ, UFRCS, FGV E UFSC), assim como a sétima e a décima colocadas (UFPR e Uninove), as quais, juntas, concentram 38,4\% dos autores dos artigos da amostra, localizam-se nas regiões Sul e Sudeste. A propósito, Souza et al. (20II) salientam que a concentração geográfica está relacionada com a evolução da quantidade e qualidade dos pesquisadores e suas interações com a comunidade científica.

Vale ressaltar a exclusão de 2I autores, por não terem sido localizados currículos ou informações que identificassem as IEs respectivas. Destaca-se ainda que outros dez autores deixaram de informar o vínculo institucional ou são provenientes de outros tipos de instituição (privadas ou públicas).

Baseada em uma análise mais criteriosa sobre a origem dos autores, foram identificados artigos desenvolvidos com base na cooperação entre IES, porém em quantidade inferior à dos artigos elaborados sem a necessidade de parceria entre instituições, representando aproximadamente $35 \%$ da amostra. Além disso, verificou-se que cerca de $4 \%$ dos artigos produzidos em cooperação reuniram parceiros oriundos de mais de três IEs. A propósito, 
alguns estudiosos ressaltam a importância de uma maior interação de autores, haja vista que a iniciativa influencia positivamente a qualidade dos artigos, em consequência do rico intercâmbio de informações (RODRIGUEs; CARRIERI, 200I; BERTERO; VASCONCELOS; BINDER, 2003; GAZDA; QUANDT; GIULIANI, 20I0).

\section{CARACTERÍSTICAS METODOLÓGICAS DOS ARTIGOS}

Quanto aos aspectos metodológicos, observou-se uma maior concentração de pesquisas teórico-empíricas, ou seja, que se dedicam a reconstruir teorias, conceitos, ideias, ideologias e polêmicas, visando ao aprimoramento dos fundamentos teóricos, além de, à luz da realidade, produzir e analisar dados, com base na observação dos fatos (DEMO, 1994). É importante salientar que, para fins desta pesquisa, a pesquisa empírica é considerada, de acordo com Demo (2000), uma pesquisa fatual da realidade, cujo desenvolvimento contempla a produção e a análise de dados com o controle empírico e fatual, enquanto a pesquisa teórica, segundo Demo (2000, p. 20), é "dedicada a reconstruir teoria, conceitos, ideias, ideologias, polêmicas, tendo em vista, em termos imediatos, aprimorar fundamentos teóricos”. A classificação teórico-empírica contempla as duas proposições de forma agregada. O Gráfico 2 apresenta os principais tipos de pesquisa observados nos 103 artigos da amostra.

Gráfico 2 Tipo de pesquisa apresentada nos artigos

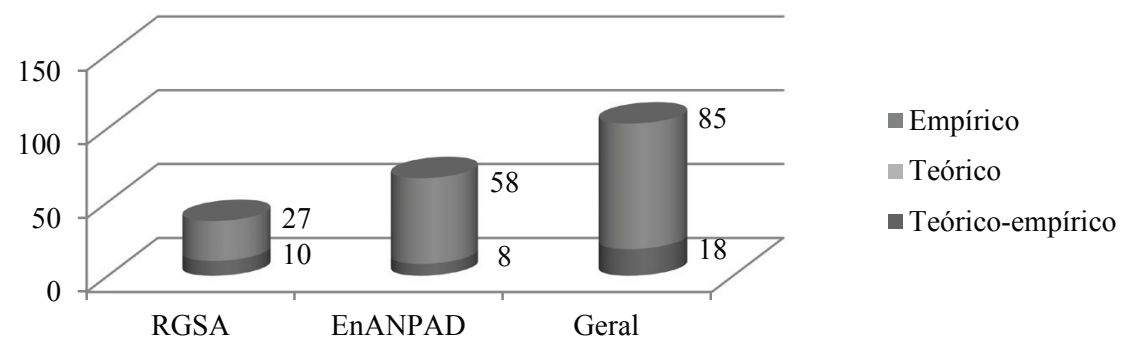


O Gráfico 2 evidencia que as pesquisas se classificam, preponderantemente, como teórico-empíricas, não se identificando pesquisas meramente empíricas. Nesse sentido, e considerando o tema e o período de análise, constatou-se que a maioria dos artigos busca a utilização de dados para comprovar teses de pesquisas relacionadas à sustentabilidade.

Verificou-se, ainda, a classificação da pesquisa quanto à natureza (abordagem) do problema, que, segundo Richardson (2009), pode ser qualitativa, quantitativa ou qualiquantitativa, admitindo-se que a pesquisa qualitativa consiste, conforme Bardin (2009), na dedução específica acerca de um acontecimento ou uma variável de inferência precisa, sem utilização de métodos estatísticos, que propiciam inferências gerais. Enquanto isso, a pesquisa quantitativa refere-se a aplicação de técnicas estatísticas no tratamento dos dados e, por meio destas, visa medir relações entre as variáveis e quantificar os resultados da investigação (RICHARDSON, 2009). Nesse sentido, a pesquisa quali-quantitativa contempla as duas características, adotando a utilização de técnicas estatísticas e aprofundando-se a interpretação dos fenômenos e atribuição de significados aos dados obtidos. Tal distribuição pode ser verificada na Tabela 4 .

Tabela 4 Distribuição quantitativa dos artigos quanto à natureza do problema

\begin{tabular}{|lllll|} 
Mídia & \multicolumn{2}{l}{ Natureza do problema } & & Total \\
& Qualitativa & Quantitativa & Qualiquantitativa & \\
\hline $\begin{array}{l}\text { Revista de Gestão Sociale } \\
\text { Ambiental }\end{array}$ & 12 & 10 & 15 & 37 \\
\hline EnAnpad & 29 & 14 & 23 & 66 \\
\hline Total & 41 & 24 & 38 & 103 \\
\hline
\end{tabular}

De acordo com a Tabela 4, verifica-se uma preponderância das pesquisas qualitativas, correspondente a $39,8 \%$ da amostra, seguidas de perto pelos estudos qualiquantitativos, corroborando estudos de Gallon et al. (2008), Jabbour, Santos e Barbieri (2008) e Souza et al. (20II).

A Tabela 5 apresenta a distribuição quantitativa dos artigos da amostra por tipo de mídia e por tipo de fonte de coleta de dados. 
Tabela 5 Distribuição da amostra da pesquisa por mídia e fonte dos dados

\begin{tabular}{|c|c|c|c|c|}
\hline \multirow[t]{2}{*}{ Mídia } & \multicolumn{3}{|c|}{ Fonte de coleta de dados } & \multirow[t]{2}{*}{ Total } \\
\hline & Primária & Secundária & Primária e secundária & \\
\hline $\begin{array}{l}\text { Revista de Gestão Social e } \\
\text { Ambiental }\end{array}$ & 11 & 23 & 3 & 37 \\
\hline EnAnpad & 23 & 33 & 10 & 66 \\
\hline Total & 34 & 56 & 13 & 103 \\
\hline
\end{tabular}

De acordo com a Tabela 5, predomina o uso da fonte secundária (54,4\% dos artigos analisados). De forma mais detalhada, verificou-se que a coleta de dados deu-se principalmente com base nas demonstrações contábeis e dos relatórios de sustentabilidade (ou similares). Em seguida, identificou-se a aplicação de entrevistas como a fonte primária mais utilizada.

\section{BASES TEÓRICAS E CARACTERÍSTICAS QUALITATIVAS DAS PESQUISAS}

Em relação aos aspectos epistemológicos, primeiramente verificaram-se as abordagens, ou seja, os enfoques da sustentabilidade apresentados pelas pesquisas. Observou-se o predomínio da abordagem socioambiental nas pesquisas (50\%), seguida da abordagem ambiental ( $27 \%)$. Esses resultados indicam que os pesquisadores da área procuram analisar a sustentabilidade sob as perspectivas social e ambiental, de forma conjunta, sendo menos recorrente a análise sob uma perspectiva única, ou seja, apenas social ou apenas ambiental.

Sob este aspecto, é importante acrescentar que, apesar da sustentabilidade ter como cerne a ideia básica do Triple Bottom Line, contemplando elementos sociais, ambientais e econômico-financeiros, há pesquisas científicas que se dedicam à discussão de apenas um destes aspectos. Assim, percebeu-se que as pesquisas seguiram três vertentes de análise, uma que tinha como foco a discussão apenas sob a dimensão ambiental, outra considerando como discussão basilar da pesquisa o aspecto social e ainda pesquisas que contemplaram os dois aspectos (socioambiental). Torna-se interessante ressaltar que, de acordo com as indicações de Kanashiro (20I0), consideradas na presente pesquisa, a sustentabilidade analisada pela perspectiva social contempla os estudos relativos 
às práticas em prol do desenvolvimento social, enquanto a sustentabilidade ambiental foca-se na problemática do meio ambiente e práticas de apropriação dos recursos naturais.

A Tabela 6 evidencia, pela ótica da sustentabilidade, a lista das diretrizes mais citadas no referencial teórico dos artigos analisados.

Tabela 6 Ranking das dez diretrizes mais citadas no referencial teórico dos artigos

\begin{tabular}{|lll|}
\hline Ordem & $\begin{array}{l}\text { Diretrizes socioambientais citadas no referencial teórico } \\
\text { dos artigos }\end{array}$ & Quantidade \\
\hline $1^{\circ}$ & Instituto Ethos & 19 \\
\hline $2^{\circ}$ & Global Reporting Initiative (GRI) & 17 \\
\hline $3^{\circ}$ & Ibase & 14 \\
\hline $4^{\circ}$ & ISO 14001 & 11 \\
\hline $5^{\circ}$ & Relatório Brundtland & 7 \\
\hline $6^{\circ}$ & ISO14000 & 5 \\
\hline $7^{\circ}$ & SA 8000 & 5 \\
\hline $8^{\circ}$ & AA1000 & 5 \\
\hline $9^{\circ}$ & Agenda 21 & 4 \\
\hline $10^{\circ}$ & Conferência de Estocolmo & 3 \\
\hline $11^{\circ}$ até o último & Outras & 46 \\
\hline
\end{tabular}

Destacam-se, portanto, conforme apresentado na Tabela 6 , as diretrizes do Instituto Ethos e da GRI, seguida das diretrizes do Ibase e da certificação ISO I400I. Vale ressaltar que, com o aumento da pressão social frente a necessidade de realização e transparência das ações empresariais com o foco na área social e ambiental, foram surgindo diversas ferramentas de avaliação das práticas empresariais. Nesse contexto surgiram três reconhecidas instituições que emanam diretrizes de ações e evidenciação de práticas relativas à sustentabilidade empresarial: Global Reporting Initiative (GRI), Instituto Brasileiro de Análises Sociais e Econômicas (Ibase) e o Instituto Ethos de Empresas e Responsabilidade Social (Instituto Ethos).

Além disso, percebeu-se que as dimensões ambiental e social são mais recorrentes nos artigos, em detrimento da econômica, indicando que a 
pesquisa acerca do tema sustentabilidade é mais frequentemente realizada sob as perspectivas social e ambiental, evidenciando que a abordagem socioambiental da sustentabilidade é mais comum nas pesquisas. Ressaltese que, com base na dimensão abordada pelas pesquisas da amostra, a escolha da metodologia para métrica da sustentabilidade concentrou-se nestas duas dimensões de forma individualizada (social ou ambiental) ou conjunta (socioambiental).

Quanto à mensuração da sustentabilidade, a Tabela 7 apresenta as principais métricas utilizadas nas pesquisas analisadas.

Tabela 7 Principais métricas da sustentabilidade aplicadas nas pesquisas

\begin{tabular}{|llll|}
\hline Abordagem & Ordem & Métrica & Quantidade \\
\hline Ambiental & $1^{\circ}$ & Nível de evidenciação de indicadores ambientais & 4 \\
& $2^{\circ}$ & Investimento ambiental & 2 \\
& $3^{\circ}$ & Certificação ambiental & 2 \\
& $4^{\circ}$ & Proposta pelo autor & 2 \\
\hline Social & $5^{\circ}$ & Outra & 8 \\
& $1^{\circ}$ & Proposta pelo autor & 5 \\
\hline Socioambiental & $2^{\circ}$ & Modelo de Hopkins & 2 \\
& $3^{\circ}$ & Outra & 3 \\
& $1^{\circ}$ & Proposta pelo autor & 4 \\
\hline $2^{\circ}$ & Metodologia de Epstein & 2 \\
\hline $4^{\circ}$ & Diretrizes GRI & 2 \\
\hline
\end{tabular}

De acordo com a Tabela 7 , as pesquisas com abordagem ambiental têm foco no nível de evidenciação de indicadores ambientais, relacionando o desempenho ambiental ao nível de divulgação das empresas. Enquanto isso, verificou-se que no âmbito da sustentabilidade social e da sustentabilidade socioambiental, as pesquisas propunham indicadores que representassem os níveis de sustentabilidade. Além dessas propostas dos autores, destacase a aplicação do Modelo de Hopkins e da Metodologia de Epstein. No que se refere à Metodologia de Epstein, utilizada na análise dos relatórios das empresas para identificar práticas comuns de sustentabilidade, esta 
considera que somente é possível integrar aspectos sociais e ambientais na estratégia empresarial quando as empresas conseguem estabelecer uma justificativa de negócios para um bom desempenho socioambiental (EPSTEIN; ROY, 2003).

Importa ainda verificar o constructo sob o qual foram desenvolvidos os artigos, ou seja, a epistemologia das pesquisas sobre o tema sustentabilidade. Neste sentido, a Tabela 8 apresenta o ranking das principais teorias e modelos utilizados nas pesquisas.

Tabela 8 Ranking das oito principais teorias/modelos apresentadas nas pesquisas

\begin{tabular}{|c|c|c|c|c|}
\hline \multirow[t]{2}{*}{ Ordem } & \multirow[t]{2}{*}{ Constructo } & \multicolumn{2}{|c|}{ Mídia / Quantidade de artigos } & \multirow[t]{2}{*}{ Total } \\
\hline & & $\begin{array}{l}\text { Revista de Gestão } \\
\text { Social e Ambiental }\end{array}$ & EnAnpad & \\
\hline 10 & Teoria dos Stakeholders & 3 & 9 & 12 \\
\hline $2^{\circ}$ & Proposto pelos autores & 0 & 9 & 9 \\
\hline $3^{\circ}$ & Modelo de Hopkins & 1 & 2 & 3 \\
\hline $4^{\circ}$ & $\begin{array}{l}\text { Pirâmide da Responsabilidade Social } \\
\text { Corporativa }\end{array}$ & 2 & 1 & 3 \\
\hline $5^{\circ}$ & Teoria da Legitimidade & 0 & 3 & 3 \\
\hline $6^{\circ}$ & Teoria da Divulgação Voluntária & 0 & 3 & 3 \\
\hline $7^{\circ}$ & $\begin{array}{l}\text { Modelo ECP - Estrutura-Conduta- } \\
\text { Performance }\end{array}$ & 0 & 3 & 3 \\
\hline $8^{\circ}$ & Modelo de Gestão de RSE & 3 & 0 & 3 \\
\hline $9^{\circ}$ até o último & Outros & 30 & 21 & 51 \\
\hline Total & & 39 & 51 & 90 \\
\hline
\end{tabular}

De acordo com a Tabela 8, a maioria dos artigos analisados teve como arcabouço teórico a Teoria dos Stakeholders. Segundo Freeman e Reed (I983) e Jensen e Meckling (I976), sob a perspectiva dessa teoria, a gestão empresarial deve observar um conjunto de partes interessadas, que excede apenas o grupo de credores shareholders managers, operado em profundidade pela Teoria da Agência e pela Teoria dos Shareholders. Complementando, Donaldson e Preston (1995) destacam que a referida teoria é considerada uma alternativa para minimizar eventuais conflitos entre gerentes e acionistas. 
Vale ressaltar que em alguns estudos foi percebida a abordagem de mais de uma teoria ou modelo. Nesses casos, observou-se com maior frequência a associação entre os constructos Teoria dos Stakeholders e Modelo de Hopkins. Entretanto, em nove artigos os autores propuseram seus próprios modelos de sustentabilidade, enquanto em outros I3 não houve menção a nenhuma teoria ou modelo, mas apenas discussão do tema sustentabilidade em determinado contexto.

Para um melhor entendimento, apresentam-se na sequência alguns detalhes importantes acerca de algumas bases teóricas ou modelos utilizados nas pesquisas da amostra (Tabela 8).

O Modelo de Hopkins, terceiro constructo mais utilizado nas pesquisas, relaciona-se aos aspectos referentes à responsabilidade social, sob três níveis: os princípios de responsabilidade social, os processos da capacidade de resposta social e os resultados e ações de responsabilidade social. Assim, o modelo de Hopkins analisa tais aspectos visando servir de apoio à realização de um constante controle do desempenho quanto à responsabilidade social (DAHER et al., 2007).

O quarto constructo mais abordado consiste na Pirâmide da responsabilidade social corporativa, que é uma avaliação constituída por quatro dimensões da definição de responsabilidade social: responsabilidade econômica, responsabilidade legal, responsabilidade ética e responsabilidade discricionária (BUSH; RIBEIRO, 2009).

A Teoria da Legitimidade aduz que as empresas buscam se tornar legítimas no mercado com base nas normas ou posturas aceitas pela sociedade e que estas podem mudar com o passar do tempo (ISLAM; DEEGAN, 2008).

Enquanto que o sexto constructo observado, a Teoria da Divulgação Discricionária, analisa os incentivos que as empresas possuem para fazer disclosure de informações de forma voluntária (VERRECCHIA, 200I).

Por fim, de acordo com Abreu (200I), o modelo ECP - Estrutura-CondutaPerformance consiste no modelo teórico de análise estrutural que busca definir a estratégia empresarial e que considera o desempenho de uma empresa como reflexo de suas práticas competitivas ou conduta no mercado. 


\section{CONSIDERAÇÕES FINAIS}

O objetivo do presente estudo consistiu em investigar a produção científica em Administração direcionada para o tema sustentabilidade, com base na consulta aos anuais do EnAnpad (2003-2010) e as doze edições quadrimestrais da Revista de Gestão Social e Ambiental (2007-2010). De forma mais pontual, procurou-se identificar as características de autoria dos artigos selecionados, analisar os procedimentos metodológicos utilizados nesses estudos e explorar as bases teóricas e características qualitativas das pesquisas.

A amostra reuniu Io3 artigos publicados nas mídias já mencionadas. Os resultados da pesquisa evidenciaram um substancial aumento do número de artigos sobre o tema sustentabilidade publicados nos dois veículos analisados, com produção mais intensiva no triênio 2007-2009, o que evidencia a consolidação e o amadurecimento da área após esse período.

Dentre os resultados encontrados em relação à autoria dos artigos analisados, destaca-se que a média de autores por trabalho evoluiu, pois nos anos iniciais da pesquisa era de 2 autores e no último ano de análise a autoria foi de, em média 3,4 autores por artigo, evidenciando uma tendência de elaboração de artigos em parceria. Além disso, identificou-se que a maioria dos artigos tem dois ou três coautores, e também que o gênero masculino predomina nessa atividade. Adicionalmente, constatou-se que os autores com níveis mais elevados de titulação são mais frequentes nas pesquisas analisadas.

No que concerne à participação das Instituições de Ensino Superior, percebeu-se uma maior presença de autores de origem das IEs das regiões Sul e Sudeste, como usp, ufrgs e fGV e ufrJ. Além disso, verificou-se que a maioria dos artigos foi desenvolvida sem a necessidade de cooperação interinstitucional.

Em relação aos aspectos metodológicos, constatou-se uma predominância dos estudos teórico-empíricos. Percebeu-se ainda uma maior incidência de estudos qualitativos, seguidos de perto por estudos qualiquantitativos, significando que são utilizadas abordagens metodológicas diferentes e complementares, como forma de se obter mais qualidade nas pesquisas. 
Além disso, a maioria dos estudos utilizou dados secundários para o desenvolvimento das pesquisas.

Sobre os aspectos epistemológicos das pesquisas, constatou-se que a maioria dos artigos investigados adota a abordagem socioambiental, indicando que os pesquisadores se preocupam em analisar a sustentabilidade sob os enfoques social e ambiental, conjuntamente, o que é confirmado com base na análise das dimensões da sustentabilidade mais contempladas nas pesquisas.

Quanto à análise das frequências de citação das diretrizes nos artigos, detectou-se que o Instituto Ethos, a GRI e o Ibase são predominantemente estudados nos artigos relacionados à sustentabilidade. Além disso, nos artigos analisados prevalecem publicações que apresentam como arcabouço teórico a Teoria dos Stakeholders, seguida por artigos em que os autores propõem seus próprios modelos teóricos de sustentabilidade.

No que tange às métricas de mensuração da sustentabilidade, o nível de evidenciação de indicadores ambientais é mais utilizado nas pesquisas relacionadas à sustentabilidade com abordagem ambiental. Em relação às pesquisas sobre sustentabilidade social e sustentabilidade socioambiental, as métricas mais apresentadas pelos artigos foram propostas pelos seus próprios autores.

Os resultados apresentados neste estudo autorizam inferir algumas tendências e perspectivas quanto às pesquisas sobre sustentabilidade, contribuindo para futuras pesquisas acadêmicas, além de servir de referência para pesquisadores que venham a se interessar pelo panorama geral da produção científica em sustentabilidade.

Considerando as limitações relacionadas à base de coleta da investigação (um evento e um periódico), recomenda-se que o estudo seja expandido a outros veículos de publicação da produção científica em sustentabilidade, com foco na gestão empresarial, para contribuir com aqueles que iniciem pesquisas sobre a temática e também com aqueles que já são pesquisadores e precisem ficar atualizados com as características metodológicas e epistemológicas da produção científica em sustentabilidade. 


\section{REFERÊNCIAS}

ABREU, M. C. S. Modelo de avaliação da estratégica ambiental: uma ferramenta para tomada de decisão. 2001. 218 f. Tese (Doutorado em Engenharia de Produção) Programa de Pós-Graduação em Engenharia de Produção, Universidade Federal de Santa Catarina - UFSC, Florianópolis/SC, 2001.

AFONSO, M. H. F.; SOUZA, J. V. de; ENSSLIN, S. R.; ENSSLIN, L. Como construir conhecimento sobre o tema de pesquisa? Aplicação do processo proknow-c na busca de literatura sobre avaliação do desenvolvimento sustentável. Revista de Gestão Social e Ambiental, v. 5, n. 2, p. 47-62, 2011.

ARAÚJO, E. A. T.; OLIVEIRA, V. do C.; SILVA, W. A. C. Estudo bibliométrico da produção científica sobre contabilidade gerencial. In: SEMEAD, 12., 2009, São Paulo. Anais... São Paulo: USP, 2009.

BARBIERI, J. C. Gestão ambiental empresarial: conceitos, modelos e instrumentos. São Paulo: Saraiva, 2007.

BARBOSA, P. R. A. Índice de sustentabilidade empresarial da Bolsa de Valores de São Paulo (ISE-Bovespa): exame da adequação como referência para aperfeiçoamento da gestão sustentável das empresas e para formação de carteiras de investimento orientadas por princípios de sustentabilidade corporativa. 2007. 150 f. Dissertação (Mestrado em Administração) - Universidade Federal do Rio de Janeiro - UFRJ, Instituto Coppead de Administração, Rio de Janeiro/RJ, 2007.

BARDIN, L. Análise de conteúdo. 3.ed. Lisboa: Edições 70, 2004.

BARDIN, L. Análise de conteúdo. 5.ed. Lisboa: Edições 70, 2009.

BERTERO, C. O.; VASCONCELOS, F. C.; BINDER, M. P. Estratégia empresarial: a produção científica brasileira entre 1991 e 2002. Revista de Administração de Empresas, v. 43, n. 4, p. 48-63, 2003.

BEUREN, I. M.; SOUZA, J. C. de. Em busca de um delineamento de proposta para classificação dos periódicos internacionais de contabilidade para o Qualis Capes. Revista de Contabilidade \& Finanças, São Paulo, v. 19, n. 46, p. 44-58, jan./abr. 2008.

BUSH, S. E.; RIBEIRO, H. Responsabilidade socioambiental empresarial: revisão da literatura sobre conceitos. Revista de Gestão Integrada em Saúde do Trabalho e Meio Ambiente, v. 4, n. 2, p. 1-25, 2009.

CARDOSO, R. L.; MENDONÇA NETO, O. R. de; RICCIO, E. L; SAKATA, M. C. G. Pesquisa científica em contabilidade entre 1990 e 2003. Revista de Administração de Empresas, v. 43, n.1, p. 34-45, 2005.

CHUNG, K. H.; PAK, H. S.; COX, R. A. K. Patterns of research output in the accounting literature: a study of the bibliometric distributions. Abacus, v. 28, n. 2, p. $168-185,1992$. 
COELHO, M. Q. Indicadores de performance para projetos sociais: a perspectiva dos stakeholders. Revista Alcance, v. 11, n. 3, p. 423-444, 2004.

COOPER, H. M.; LINDSAY, J. J. Research synthesis and meta-analysis. In: BICKMAN, L.; ROG, D. J. Handbook of applied social research methods. Thousand Oaks: Sage Publications, 1998, p. 315-342.

CORREA, D. A.; SACOMANO NETO, M.; SPERS, V. R. E; GIULIANI, A. C. Inovação, Sustentabilidade e Responsabilidade Social: análise da experiência de uma empresa de equipamentos pesados. RGSA - Revista de Gestão Social e Ambiental, v.4, n.3, p. 90-105, 2010.

DAHER, W. M.; OLIVEIRA, M. C.; CALS, B. O.; PONTE, V. M. R. Responsabilidade Social Corporativa segundo o modelo de Hopkins: um estudo nas empresas do setor energético do nordeste brasileiro. Revista de Gestão Social e Ambiental, v. 1, n. 1, p. 31-46, 2007.

DELAI, I.; TAKAJASHI, S. Uma proposta de modelo de referência para mensuração da sustentabilidade corporativa. Revista de Gestão Social e Ambiental, v. 2, n. 1, p. 19-40, 2008. DE LUCA, M. M. M.; GOMES, C. A. S.; CORRÊA, D. M. M. C.; DOMINGOS, S. R. M. Participação feminina na produção científica em contabilidade publicada nos anais dos eventos Enanpad, Congresso USP de Controladoria e Contabilidade e Congresso Anpcont. Revista de Contabilidade e Organizações, v. 5, n. 11, p. 145-164, 2011.

DEMO, P. Pesquisa e construção do conhecimento: metodologia científica no caminho de Habermas. Rio de Janeiro: Tempo Brasileiro, 1994.

DEMO, P. Metodologia do conhecimento científico. São Paulo: Atlas, 2000.

DONALDSON, T.; PRESTON, L. E. The stakeholder theory of the corporation: concepts, evidence, and implications. The Academy of Management Review, v. 20, n.1, p. 65-91, 1995.

EPSTEIN, M. J.; ROY, M. J. Making the business case for sustainability. linking social and environmental actions to financial performance. Journal of Corporate Citizenship, v. 9, n.1, p. 79-96, 2003.

FARIAS, K. T. R.; FARIAS, M. R. S. Influência do desempenho ambiental na estratégia de divulgação ambiental das empresas abertas brasileiras. In: EnANPAD, 33., 2009, São Paulo. Anais... São Paulo: Anpad, 2009.

FOGARTY, T. J. Sustained research productivity in accounting: a study of the senior cohort. Global Perspectives in Accounting Education, v. 1, n. 1, p. 31-58, 2004.

FONSECA, E. N. Bibliometria: teoria e prática. São Paulo: Cultrix, 1986.

FREEMAN, R. E.; REED, D. L. Stockholders and stakeholders: a new perspective on corporate governance. California Management Review, v. 25, n. 3, p. 88-106, 1983.

GALLON, A. V.; SOUZA, F. C. de; ROVER, S.; BELLEN, H. M. V. Um estudo longitudinal da produção científica em administração direcionada à temática ambiental. Revista Alcance, 15, n. 1, p. 81-101, 2008. 
GAZDA, E.; QUANDT, C. O.; GIULIANI, A. C. Inovação, sustentabilidade e responsabilidade social: análise da experiência de uma empresa de equipamentos pesados. Revista de Gestão Social e Ambiental, São Paulo, v. 4, n. 3, p. 90-105, 2010.

ISLAM, M. A.; DEEGAN, C. Motivations for an organization within a developing country to report social responsibility information: evidence from Bangladesh. Accounting, Auditing \& Accountability Journal, v. 21, n. 6, p. 850-868, 2008.

JABBOUR, C. J. C.; SANTOS, F. C. A.; BARBIERI, J. C. Gestão ambiental empresarial: um levantamento da produção científica brasileira divulgada em periódicos da área de administração entre 1996 e 2005. Revista de Administração Contemporânea, v. 12, n. 3, p. 689-715, 2008.

JENSEN, M. C.; MECKLING, W. H. Theory of the firm: managerial behavior, agency costs and ownership structure. Journal of Financial Economics, v. 3, n. 4, p. 305-360, 1976.

KANASHIRO, V. U. Produção acadêmica brasileira sobre sustentabilidade: análise da base Scielo Brasil, 10/2010, In: ANPPAS, 5., 2010, Florianópolis/SC. Anais... Florianópolis/SC: ANPPAS, 2010.

LADEIRA, W. J.; SANTINI, F. de O.; ARAÚJO, C. F. Práticas sustentáveis na instituições de ensino superior: uma proposta de taxonomia baseada na percepção ambiental dos alunos do curso de administração. Administração: Ensino e Pesquisa, v. 13, n. 4, p. 735-761, 2012.

LAGES, R. T. da S.; LAGES, R. T. da S.; FRANÇA, S. L. B. Indicadores de desempenho com conceito do Triple Bottom Line e a metodologia Balanced Scorecard. In:

Congresso Nacional De Excelência Em Gestão, 6., 2010, Niterói/RJ. Anais... Niterói/RJ: Firjan, 2010.

LEITE FILHO, G. A. Padrões de produtividade de autores em periódicos e congressos na área de contabilidade no Brasil: um estudo bibliométrico. Revista de Administração Contemporânea, v. 12, n. 2, p. 533-554, 2008.

MACHADO, M. R.; NASCIMENTO, A. R.; MURCIA, F. Dal-Ri. Análise crítica epistemológica da produção científica em contabilidade social e ambiental no Brasil. In: Congresso USP Controladoria E Contabilidade, 9., 2009, São Paulo. Anais... São Paulo: USP, 2009.

MACIAS-CHAPULA, C. A. O papel da informetria e da cienciometria e sua perspectiva nacional e internacional. Ciência da Informação, v. 27, n. 2, p. 134-140, 1998.

MORETTI, S. L. A.; CAMPANÁRIO, M. de A. A produção intelectual brasileira em responsabilidade social empresarial - RSE sob a ótica da bibliometria. Revista de Administração Contemporânea, v. 13, Edição Especial, 2009.

NASCIMENTO, A. R.; SANTOS, A.; SALOTTI, B.; MÚRCIA, F. D. Disclosure social e ambiental: análise das pesquisas científicas veiculadas em periódicos de língua inglesa. Revista Contabilidade Vista \& Revista, v. 20, n. 1, p. 15-40, 2009. 
\& OUTROS

OLIVEIRA, M. C. Análise dos periódicos brasileiros de contabilidade. Revista Contabilidade \& Finanças, n. 29, p. 68-86, 2002.

OLIVEIRA, J. G.; BORGES, F. H.; JABBOUR, C. C. O impacto competitivo da estratégia ambiental: uma abordagem teórica. In: Simpósio Internacional de Gestão Ambiental e Saúde - SIGAS, 1., 2005, São Paulo. Anais... São Paulo: Senac, 2005.

PARENTE, A.; FERREIRA, E. Indicadores de sustentabilidade ambiental: um estudo do ecological foot print method do município de Joinville - SC. In: EnAnpad, 31., 2007, Rio de Janeiro. Anais... Rio de Janeiro: Anpad, 2007.

PEREIRA, G. M. de C.; YEN-TSANG, C.; MANZINI, R. B.; ALMEIDA, N. V. Sustentabilidade socioambiental: um estudo bibliométrico da evolução do conceito na área de gestão de operações. Produção, v. 21, n. 4, p. 610-619, 2011.

RAVELLI, A. P. X.; FERNANDES, G. C. M.; BARBOSA, S. de F. F.; SIMÃO, E.; SANTOS, S. M. A dos; MEIRELLES, B. H. S. A produção do conhecimento em enfermagem e envelhecimento: estudo bibliométrico. Texto Contexto Enferm, v. 18, n. 3, p. 506-512, 2009.

RGSA - Revista de Gestão Social e Ambiental. Foco e escopo. Disponível em: <http:// www.revistargsa.org/rgsa/about/editorialPolicies\#focusAndScope >. Acesso em: 29/10/2013.

RICHARDSON, R. J. Pesquisa social: métodos e técnicas. São Paulo: Atlas, 2009.

RODGERS, J. L.; WILLIAMS, P. F. Patterns of research produtivityan knowledge creation at the accounting review: 1967-1993. The Accounting Historians Journal, v. 1, n. 2 , p. 123-137, 1996.

RODRIGUES, M. C. P. Avaliação da gestão social nas empresas: desafios e possibilidades. In: EnAnpad, 29., 2005, Brasília. Anais... Brasília: Anpad, 2005.

RODRIGUES, S.; CARRIERI, A. A tradição anglo-saxônica nos estudos organizacionais brasileiros. Revista de Administração Contemporânea, v. 5, Edição Especial, p. 81-102, 2001.

ROSA, F. S. da; ENSSLIN, S. R. Tema “a gestão ambiental” em eventos científicos: um estudo exploratório nos eventos avaliados segundo critério Qualis da Capes. In: Encontro Nacional de Gestão Empresarial e Meio Ambiente, 9., 2007, Curitiba. Anais... Curitiba: Engema, 2007.

SANTOS, S. R. de O.; SOUZA, M. J. B.; FALKEMBACH, J. R. Responsabilidade social corporativa: um estudo bibliométrico da produção dos EnAnpads na última década. In: Simpósio de Excelência em Gestão e Tecnologia, 5., 2008, Resende. Anais... Resende: AEDB, 2008.

SGARBI, V. S.; LIMA, M. T. A. de; SANTOS, C. de F. S. O.; FALCÃO, M. C. Os jargões da sustentabilidade: uma discussão a partir da produção científica nacional. In: Encontro Nacional de Gestão Empresarial e Meio Ambiente, 10., 2008, Porto Alegre. Anais... Porto Alegre: Engema, 2008. 
SILVA, A. J.; TOLEDO FILHO, J. R.; PINTO, J. Análise bibliométrica dos artigos sobre controladoria publicados em periódicos dos programas de pós-graduação em ciências contábeis recomendados pela Capes. Revista ABCustos, v. 4, n. 1, p. 36-52, 2009.

SIN, S. C. J. International coauthorship and citation impact: a bibliometric study of six LIS Journals,1980-2008. Journal of the American Society for Information Science and Technology, v. 62, n. 9, p. 1.770-1.783, 2011.

SOUZA, F. C. de; MURCIA, F. Dal-Ri; MARCON, R. Bonding hypothesis: análise da relação entre disclosure, governança corporativa e internacionalização de companhias abertas no Brasil. Revista Contabilidade, Gestão e Governança, v. 14, n. 2, p. 62-81, 2011.

SOUZA, M. T. S.; RIBEIRO, H. C. M.; MACHADO JÚNIOR, C.; CORRÊA, R. Perfil e evolução da pesquisa em sustentabilidade ambiental: uma análise bibliométrica. In: EnAnpad, 35., 2011, Rio de Janeiro. Anais... Rio de Janeiro: Anpad, 2011.

SOUZA, M. T. S.; PARISOTTO, I.R.S.; MACHADO JUNIOR, C.; BARBIERI, J.C. Estudo bibliométrico de teses e dissertações de programas Stricto Sensu em Administração sobre Responsabilidade Social Empresarial. Administração: Ensino e Pesquisa, v. 14, n. 1, p. 63-98, 2013.

SUBRAMANYAM, K. Bibliometric studies of research collaboration: a review. Journal of Information Science, v. 6, n. 1, p. 33-57, 1983.

THEÓPHILO, C. R. Pesquisa em contabilidade no Brasil: uma análise críticoepistemológica. São Paulo, 2004. 212 f. Tese (Doutorado em Controladoria e Contabilidade) - Faculdade de Economia, Administração e Contabilidade, Universidade de São Paulo, 2004.

VELTER, A. N.; BATTISTELLA, L. F.; GROHMANN, M. Z.; CARPES, A. de M. O estudo da sustentabilidade na administração: um levantamento dos "hot topics" publicados na última década. In: SEMEAD, 8., 2010, São Paulo. Anais... São Paulo: USP, 2010.

VERRECCHIA, R. E. Essays on disclosure. Journal of Accounting and Economics, v. 22, n. 1, p. 97-180, 2001.

ZEFF, S. A. A study of academic research journals in accounting. Accounting Horizons, v. 10, n. 3, p. 158-177, 1996. 


\section{DADOS DOS AUTORES}

\section{MÁRCIA MARTINS MENDES DE LUCA^ marciadeluca@ufc.br} Doutora em Controladoria e Ciências Contábeis pela FEA/USP

Instituição de vinculação: Universidade Federal do Ceará

Fortaleza/CE - Brasil

Áreas de interesse em pesquisa: Responsabilidade Social Corporativa, Sustentabilidade, Governança Corporativa e Reputação Corporativa.

*Universidade Federal do Ceará - Programa de Pós-Graduação em Administração e Controladoria Av. da Universidade, 2486 Benfica Fortaleza/CE 60020-180

\section{VANESSA INGRID DA COSTA CARDOSO nessaingrid@gmail.com}

\section{Mestre em Administração e Controladoria pela UFC}

Instituição de vinculação: Universidade da Integração Internacional da Lusofonia Afrobrasileira e Faculdade Lourenço Filho

Fortaleza/CE - Brasil

Áreas de interesse em pesquisa: Controladoria, Contabilidade financeira, Governança corporativa, Educação contábil, Sustentabilidade e Responsabilidade socioambiental.

\section{ALESSANDRA CARVALHO DE VASCONCELOS alegallon@terra.com.br Doutora em Engenharia de Produção pela UFSC \\ Instituição de vinculação atual: Universidade Federal do Ceará \\ Fortaleza/CE - Brasil \\ Áreas de interesse em pesquisa: Controladoria, Contabilidade financeira, Governança corporativa, Inovação, Responsabilidade corporativa, Sustentabilidade e Internacionalização.}

AYRTON BEZERRA PONTES ayrton@alu.ufc.br Bacharel em Ciências Contábeis pela UFC

Instituição de vinculação: Universidade Federal do Ceará

Fortaleza/CE - Brasil

Áreas de interesse em pesquisa: Sustentabilidade e Responsabilidade socioambiental. 